\title{
Synthesis of Graphene Supported Pd Nanoparticles for Amperometric NO Gas Sensors
}

\author{
Huan Wang* \\ Department of Materials Science, Jilin Provincial Key Laboratory of Architectural Electricity\&Comprehensive Energy \\ Saving, Jilin jianzhu University, Changchun 130118, China \\ E-mail address:whuan@ciac.ac.cn
}

\begin{abstract}
The Pd Nanoparticles attached on graphene nanosheet (GNS) were synthesized by a simple method. The morphology, structure and component for the a obtained graphene/Pd hybrids have been characterized by $\mathrm{X}$-ray diffraction (XRD), transmission electron microscopy (TEM) and X-ray photoemission spectroscopy (XPS). The amperometric NO gas sensor was assembled with Graphene/Pd hybrids as the electrode material and $0.5 \mathrm{M}$ $\mathrm{NaOH}$ solution as electrolyte. It displayed a high sensitivity, together with fairly good detection times and stability. The cross-sensitivities of the sensor to existant gases $\left(\mathrm{CO}, \mathrm{H}_{2} \mathrm{~S}\right)$ are rather small.
\end{abstract}

Keywords-Graphene; Amperometric ; Sensore; Sensitivity; Selectivity

\section{INTRODUCTION}

Nitric oxide is a well-known significant air pollutant. Environmental Protection Agency (US) has established National Ambient Air Quality Standards that requires oxides of nitrogen (nitric oxide and nitrogen dioxide) level to be below $0.053 \mathrm{ppm}$ (annual average). Extended inhalation of high concentration of nitric oxide can lead to hypotension, sepsis, hemorrhage and other adverse conditions. ${ }^{[1]}$ In addition, nitric oxide gas can be oxidized in the air into nitrogen dioxide, which can be toxic to lung tissue and is a major contributor for ground-level ozone formation. Continued measurement of nitric oxide may also be necessary to make sure air nitric oxide level is below the limit set by United State Occupational Safety and Health Administration (25 ppm/8 hours) in high risk areas.

Amperometric gas sensors (AGS) are had on measurements of steady-state currents which are proportional to the concentrations of the analytes. AGS have been developed to monitor many electrochemically active gases, such as $\mathrm{CO}, \mathrm{NO}, \mathrm{NO}_{2}, \mathrm{O}_{2}, \mathrm{H}_{2}, \mathrm{H}_{2} \mathrm{~S}, \mathrm{CH}_{4}$, $\mathrm{NH}_{3}, \mathrm{C}_{2} \mathrm{H}_{5} \mathrm{OH} .{ }^{[2]}$ Amperometric $\mathrm{NO}$ gas sensor has attracted a great deal of attention, which due to that can provide fast, accurate, sensitive and real-time determination. Blurton and Sedlak explored Teflon-bond gold electrode to detect nitric oxide. Sun, et al. ${ }^{[1]}$ have reported that employing reticulated vitreous carbon as electrode active material has achieved high Electrocatalytic properties. Do, et al. ${ }^{[3]}$ used the sensor array for monitoring gas mixtures such as $\mathrm{NOx}, \mathrm{CO}, \mathrm{O}_{2}$ and $\mathrm{SO}_{2}$.
Presently, commercial amperometric gas sensors are usually employed porous polytetrafluoroethylene (PTFE) membranes contains Pt Nanoparticles (NPs) as working electrodes. However, these catalysts remain very expensive, limited the development of AGS. Therefore, less-expensive of electrocatalytic materials have been suggested as a good replacement for $\mathrm{Pt}$ and $\mathrm{Au}$. The graphene are known to have all the essential properties like high surface area, excellent electrical conductivity, corrosion resistance, and surface properties which are required for electrocatalytic materials. More often than not, supports for $\mathrm{Pt}$ catalysts also have an important influence on the catalytic efficiency of Pt-based catalysts. [4] Carbon materials are studied widely as catalysts supports in AGS. Among various carbon supports, graphene is a promising support for noble metal-based catalysts due to its high electronic conductivity, good chemical stability and large surface to volume ratio.

In this paper, the GNS/Pd hybrids have been synthesized by a simple solvothermal method and the obtained samples have been characterized by XRD, XPS, TEM and EDX. The amperometric NO gas sensors were assembled with $\mathrm{C} / \mathrm{Pd}$ hybrids as the active electrode material and $1 \mathrm{M} \mathrm{NaOH}$ solution as electrolyte. This kind of sensor shows potential application in form aldehyde gas detection in this range due to its excellent sensitivity and stable response.

\section{EXPERIMENTAL}

The starting materials used in the experiments were natural graphite (99 wt. \% purity, Oingdao Yingshida Graphite Co. Ltd ), $\mathrm{NaNO}_{3}$ (Tianjin Guangfu Chemicals Co., Ltd), $\mathrm{H}_{2} \mathrm{SO}_{4}$ (98 wt. \%, analytical reagent $=$ A. R., Beijing Beihua Chemicals Co., Ltd), $\mathrm{H}_{2} \mathrm{O}_{2}$ (30 wt. \%, A. R., Beijing Beihua Chemicals Co., Ltd), $\mathrm{HCl}$ (37 wt. \%, A. R., Beijin Beihua Chemicals Co., Ltd), ethylene glycol (99 .99 wt. \%, A. R., Beijing Beihua Chemicals Co., Ltd), $\mathrm{PdCl}_{2}$ (99.99 wt. \%, A. R., Beijing Beihua Chemicals Co., Ltd), $\mathrm{NaOH}$ (99.99 wt. \%, A. R., Beijing Beihua Chemicals Co., Ltd).

\section{A. Synthesis of graphene oxide}

GO was prepared using a modified Hummers method from graphite powders. ${ }^{[5]} \mathrm{NaNO}_{3}(1.5 \mathrm{~g})$ was mixed with concentrated sulfuric acid $(67.5 \mathrm{ml})$ at room temperature. 
Then natural graphite $(2.0 \mathrm{~g})$ was added to the solution while stirring, this mixture was cooled to $0{ }^{\circ} \mathrm{C}$ in an ice bath, followed by slow addition of $9.0 \mathrm{~g} \mathrm{KMnO}_{4}$, and the reaction mixture was allowed to stand for five days at room temperature with stirring. On completion of the reaction, $100 \mathrm{~mL}$ of 5 wt. $\% \mathrm{H}_{2} \mathrm{SO}_{4}$ aqueous solution was added to the mixture over about $1 \mathrm{~h}$ with stirring for $2 \mathrm{~h}$. Then $6 \mathrm{~mL}$ of $\mathrm{H}_{2} \mathrm{O}_{2}$ (30 wt $\%$ aqueous solution) was added to the above liquid and the mixture was stirred for $2 \mathrm{~h}$ at room temperature. Finally, the resulting suspension was filtered, washed with a mixed aqueous solution of $3 \mathrm{wt} . \%$ $\mathrm{H}_{2} \mathrm{SO}_{4} / 0.5$ wt. $\% \mathrm{H}_{2} \mathrm{O}_{2}$ and water, and dried at room temperature for $24 \mathrm{~h}$ to obtain $\mathrm{GO}$ sheets.

\section{B. Preparation of G/Pd nanoparticles composites}

The G/Pd composites were prepared by using a simple and eco-friendly solvothermal process. ${ }^{[6]}$ The Graphite oxide was dispersed into ethylene glycol (EG) $\left(0.5 \mathrm{~g} \mathrm{~L}^{-1}\right)$ followed by sonicating for more than $3 \mathrm{~h}$ to obtain the clear GO solution under ambient condition. A typical preparation of $\mathrm{G} / \mathrm{Pd}$ composites consists of the following steps: $41.6 \mathrm{mg} \mathrm{PdCl}_{2}$ was mixed with $\mathrm{EG}$ of $15 \mathrm{~mL}$, and $60 \mathrm{mg}$ GO was added into the mixture of $20 \mathrm{~mL}$ of $\mathrm{EG}$ and sonicated for $1 \mathrm{~h}$. Two solutions above were mixed together and stirred for $5 \mathrm{~h}$. Its $\mathrm{pH}$ value was adjusted to 10 by $\mathrm{NaOH}$ solution of EG and then Then $35 \mathrm{~mL}$ of solution was added into a $50 \mathrm{~mL}$ autoclave and the solution was kept under $100{ }^{\circ} \mathrm{C}$ for $5 \mathrm{~h}$ followed by cooling to ambient temperature. Its $\mathrm{pH}$ value was adjusted to about 3.5 by $\mathrm{HCl}$ and then standing overnight. The resulting suspension was washed repeatedly with hot ultrapure water $(18.2 \mathrm{MX} \mathrm{cm})$, and the composites powder was dried at $60{ }^{\circ} \mathrm{C}$ for $24 \mathrm{~h}$.

\section{Characterizations}

Transmission electron microscope (TEM), Energydispersive X-ray (EDX), and high-resolution TEM (HRTEM) (TEM, JOEL TEM-2010) with a field emission gun operating at $200 \mathrm{kV}$ were employed to inspect the morphologies, composition, and structures for samples. Xray photoelectron spectroscopy (XPS) (Thermo ESCALAB 250) was performed with an $\mathrm{Al} \mathrm{Ka}$ radiation and hemisphere detector with an energy resolution of 0.1 $\mathrm{eV}$ to reveal the chemical bonding.

\section{Electrochemical investigation}

We assembled the amperometric NO gas sensor cantaining three electrodes: the G/Pd composite coated membranes as working electrode, a platinum wire counter electrode, and a saturated calomel electrode (SCE) as the reference electrode. To fabricate working electrode, 5.0 $\mathrm{mg}$ of this sample were dispersed in $0.5 \mathrm{ml}$ ethanol form a homogenouscatalysts ink by sonication, and then the samples ink was mixed with a $2 \mu \mathrm{L}$ of $0.5 \%$ Nafion $\AA 117$ ethanol solution. The mixture was Sprayed and air-dried on the PTFE membrane at room temperature. After water evaporated, a three-electrode setup was configured with CHI 660 inter-faced to a personal computer at room temperature for the electrochemical characterization.

\section{RESULTS AND DISCUSSION}

Figure 1 shows the XRD patterns of the JCPDS card 65-2867 for Pd (a), G samples (b), and G/Pd hybrids composites (c). As we all know, the XRD pattern for the natural graphite powder shows a very strong $(002)$ peak at $26.45^{\circ}$, indicating a typical pattern of crystal graphitic structure with a layer-layer distance (d-spacing) of 0.334 $\mathrm{nm}$. a broad peak near $24.5^{\circ}$ appeared for the $\mathrm{G}$ sample (Figure $1 \mathrm{~b})$, which is 002 peak $\left(\mathrm{d}_{002}=0.365 \mathrm{~nm}\right)$ for graphite. The $\mathrm{G}$ sample shows the interlayer spacing of $\mathrm{d}_{002}$ is larger than that of graphite, which implies that the some oxide-induced O-containing groups such as carboxyl (-COOH), hydroxyl (-OH), and epoxy groups were remained. [7] Figure 1c shows that Pd particles spread on the $G$ sheets form a body-centered cubic

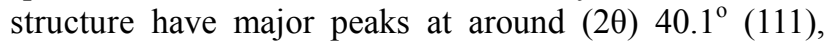
$46.7^{\circ}(200), 68.1^{\circ}(220)$, and $82.1^{\circ}(311)$. In general, the nanocrystallite size can roughly be estimated from the Scherrer formula: $D_{h k l}=K \lambda /(\beta \cos \theta)$, where $\lambda$ is the $X$ -

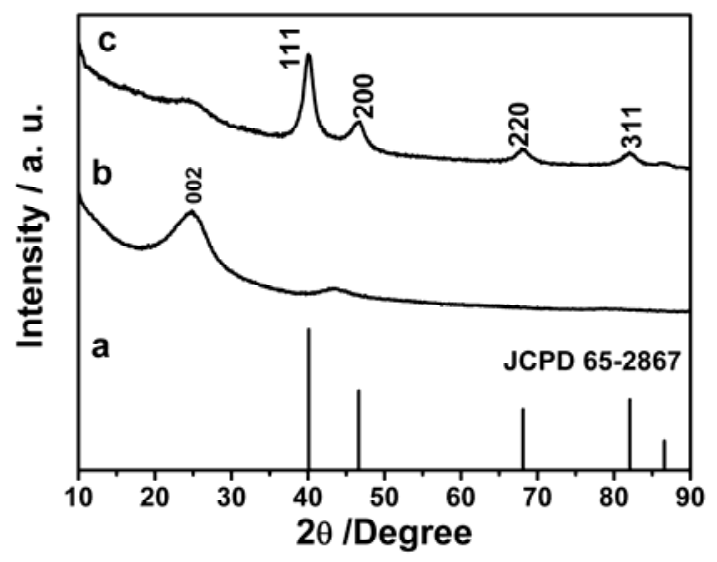

Figure 1. X-ray diffraction patterns for the JCPD card 65-2867 for Pd (a), the G sample (b), and G/Pd hybrid composite (c), wherein the Miller indices of diffracting lattice planes are indexed.

ray wavelength $(0.15418 \mathrm{~nm}), \beta$ the full-width at halfmaximum, $\theta$ the diffraction angle, $\mathrm{K}$ a constant $(0.89)$ and $\mathrm{D}_{\mathrm{hkl}}$ means the size along (hkl) direction [8]. Here we take diffraction data along all the planes to roughly calculate the size of the nanocrystallites, and the roughly estimated average crystallite sizes of Pd nanoparticles is around 5 $\mathrm{nm}$ on the surface of $\mathrm{G}$ sheets, which is in good agreement with TEM results, discussed in the following.

In order to illustrate further the composition of the G/Pd hybrids, X-ray photoelectron spectroscopy (XPS) was performed and is shown in Figure 2. As shown in the survey XPS spectrum (Figure 2a), the peaks of $\mathrm{C}, \mathrm{O}$ and $\mathrm{Pd}$ can be obviously detected, which confirmed existence of $\mathrm{C}, \mathrm{O}$ and $\mathrm{Pd}$ in the $\mathrm{G} / \mathrm{Pd}$ hybrid composites. Figure $2 \mathrm{~b}$ shows the characteristic Pd 3d bands. ${ }^{[7]}$ The two bands at ca. 340.1 and $334.8 \mathrm{eV}$ can be attributed to the $\mathrm{Pd} 3 \mathrm{~d}_{5 / 2}$ and $3 d_{3 / 2}$ binding energies respectively. The $C 1$ s peak of the G/Pd hybrid (Figure 2c) consists of four different components that correspond to carbon atoms in different functional groups: the $\mathrm{sp}^{2} \mathrm{C}(283.7 \mathrm{eV})$, the $\mathrm{sp}^{3}$ carbon 
(284.6 eV), the $\mathrm{C}$ in $\mathrm{C}-\mathrm{O}$ bonds $(286.0 \mathrm{eV})$ and carbonyl $\mathrm{C}(288.4 \mathrm{eV})$. These assignments are in agreement with previous works. ${ }^{[8]}$ The $\mathrm{O} 1 \mathrm{~s}$ XPS spectrum of the G/Pd hybrids appears at peaks of $531.7 \mathrm{eV}$ and $533.0 \mathrm{eV}$, in accordance with previous work, because it comes from the combination of $\mathrm{C}=\mathrm{O}(531.7 \mathrm{eV})$ and $\mathrm{C}-\mathrm{O}(533.0 \mathrm{eV}){ }^{[9]}$
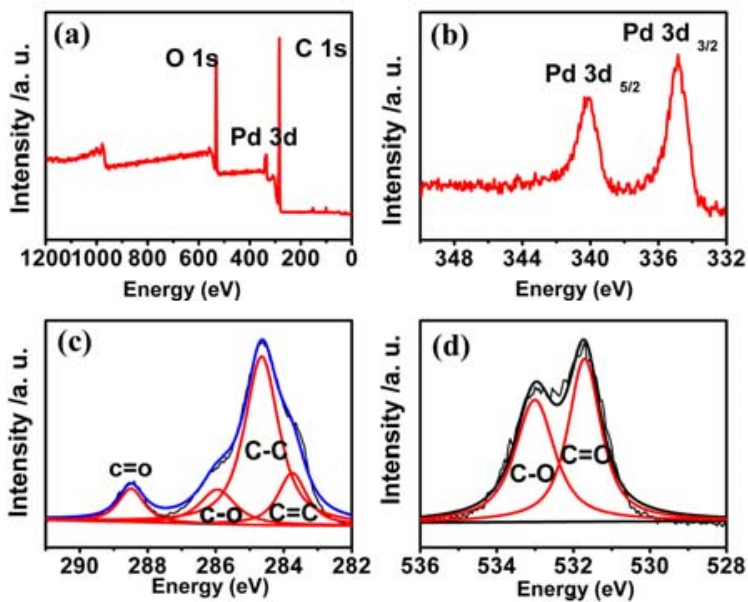

Figure 2. the survey (a), Pd 3d (b), C 1s (c) and O 1s (d) XPS spectrum of GNS/Pd hybrid composite.

The results of the above characterizations clearly show that Pd nanoparticles have been successfully decorated on the surface of GNS, and results are shown in Figure 3. As shown in Figure 3a, the obtained GNS retained a well dispersed and sheet-like morphology. They were transparent and entangled with each other. Figure $3 \mathrm{~b}$ shows the TEM image of the GNS/Pd hybrid composite, in which above-mentioned sheet conjugations are also clearly observed. It was found that small nanoparticles (black dots) were assembled on the surface of the GNS

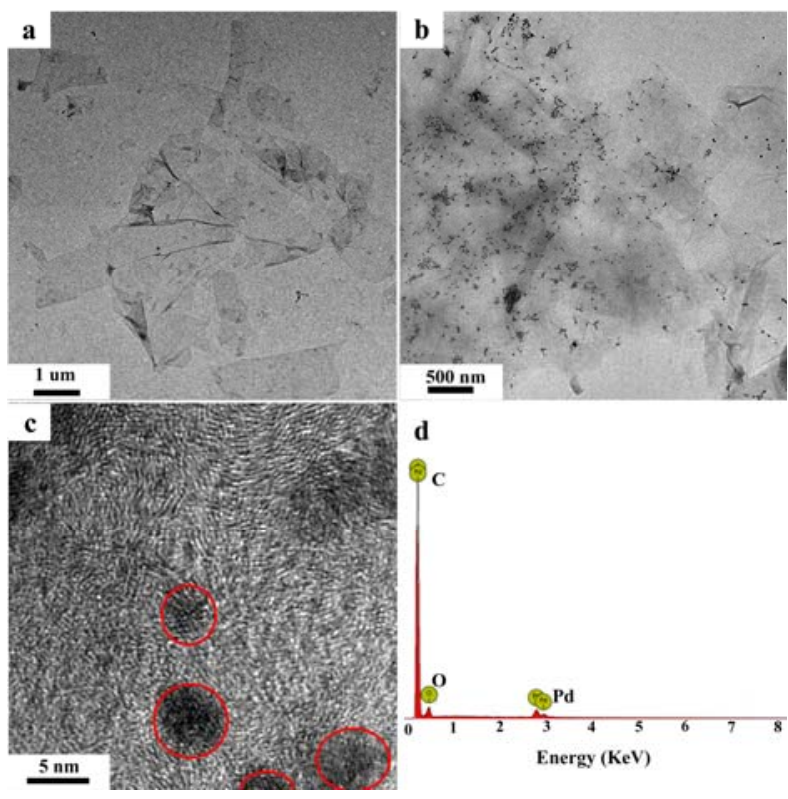

Figure 3. TEM and high-resolution TEM images for the GNS (a), GNS/Pd hybrids (b-c), as well as the energy dispersive X-ray spectrum (d) for the sample in (b). and well-distributed. Figure 3c displays the HRTEM image of the GNS/Pd hybrids composites, in which there exist a few nanocrystal particles on the GNS. In the crystalline regions indicated by red rounds, the distance $(0.224 \mathrm{~nm})$ between the adjacent lattice fringes just corresponds to the interplanar distance of Pd (111) planes, agreeing well with the $d$ (111) spacing $(0.223 \mathrm{~nm})$ (JCPDS No. 65-2867) in the literature, ${ }^{[10]}$ which does not correspond to none of the interplanar distance of graphitic lattice. The energy dispersive X-ray spectrum performed on the GNS/Pd hybrid composite (Figure 3d) suggests the existence of $\mathrm{C}$ (from the GNS), O (from the GNS), Pd (from the Pd nanoparticles on the GNS), which agreed well with XPS analysis (Figure 2a).

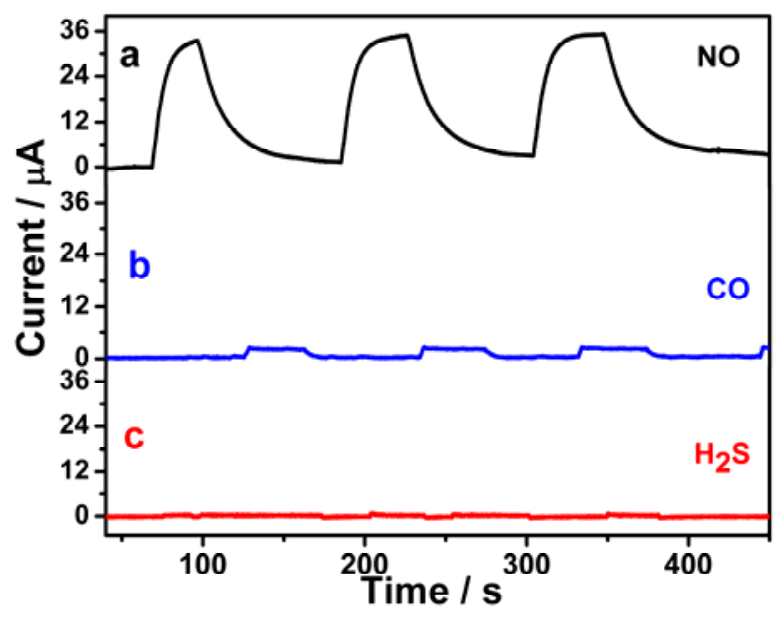

Figure 4. Amperometric i-t curves of the GNS/Pd-assembled gas sensor with $1 \mathrm{M} \mathrm{NaOH}$ as the internal electrolyte to different $10 \mathrm{ppm}$ NO, 200 ppm CO, and $100 \mathrm{ppm}_{2} \mathrm{~S}$.

In order to examine the response character of the GNS/Pd hybrids gas sensor toward to different gases such as $\mathrm{NO}, \mathrm{CO}, \mathrm{H}_{2} \mathrm{~S}$, the current-time transient curve was recorded at constant potential $650 \mathrm{mV}$ relative to the $\mathrm{Ag} / \mathrm{AgCl}$ reference electrode. Figure $4 \mathrm{a}$ shows the current responses of the gas sensor toward $10 \mathrm{ppm} \mathrm{NO}$ gas. The sensing current sharply increased from 0 to $34 \mu \mathrm{A}$ when the NO concentration was changed from 0 to $10 \mathrm{ppm}$ and the anodic potential was kept at $0.65 \mathrm{~V}$. As shown, the response time was found to be $22 \mathrm{~s}$ when the sensing current was equal to $90 \%$ steady current. It was also found that the response time for $10 \%$ steady current of $10 \mathrm{ppm}$ $\mathrm{NO}$ was $61 \mathrm{~s}$ in the test gas was switched from 10 to $0 \mathrm{ppm}$. Figure $4 \mathrm{~b}$ shows the current response of the amperometric gas sensor with GNS/Pd hybrids electrodes exposed to $\mathrm{CO}$ gas. The response time for $\mathrm{CO}$ gas is still fast. Howeever, intensity of response signal is lower than NO gas. No detectable interfering $\mathrm{H}_{2} \mathrm{~S}$ responses (Figure 4c) were observed for gas sensor as $100 \mathrm{ppm} \mathrm{H}_{2} \mathrm{~S}$ gas were introduced. These results indicate that GNS/Pd hybrids may serve as not only a sensitive material for NO gas detection but also a tool to determine the possible concentration of NO in the environment. ${ }^{[1]}$ 


\section{CONCLUSIONS}

Thin sheet GNS/Pd hybrid composites have been successfully $^{3}$ behavior to NO was also investigated. Studies showed that amperometric NO gas sensor has a fast response time, good stability, and low cost. The current response to $\mathrm{NO}$ with $1 \mathrm{M} \mathrm{NaOH}$ as the internal electrolyte was much larger than for Interfering gases such as $\mathrm{CO}$ and $\mathrm{H}_{2} \mathrm{~S}$ on the GNS/Pd hybrids assembled gas sensor.

\section{ACKNOWLEDGMENT}

Financial support by Jilin Provincial Science and Technology Development Foundation (Grant No. 20130522143JH), 12th Five-Year Plan in Science and technology of the Education Department of Jilin Province (2014-233), Ph.D. program from Jilin jianzhu University are gratefully acknowledged.

\section{REFERENCES}

[1] J. Sun, P. C. Hauser, V. Zhelyaskov, J. Lin, M. Broderick, H. Fein and X. Zhang, A New Nitric Oxide Gas Sensor Based on Reticulated Vitreous Carbon/Nafion and Its Applications [J]. Electroanalysis, 2004, 16: 1723-1729.

[2] J. R. Stetter, J. Lin, Eason, Amperometric Gas SensorssA Review [J]. Chemical Reviews, 2008, 108: 352-366.

[3] J. S. Do, P. J. Chen, Amperometric sensor array for NOx, CO, O2 and SO2 detection $[\mathrm{J}]$. Sensors and Actuators B: Chemical, 2007, 122: $165-173$.
[4] K. J. Chen, K. Pillai Chandrasekara, J. Rick, C. J. Pan, S. H. Wang, C. C. Liu, B. J. Hwang, Bimetallic PtM (M=Pd, Ir) nanoparticle decorated multi-walled carbon nanotube enzyme-free, mediatorless amperometric sensor for $\mathrm{H} 2 \mathrm{O} 2$ [J]. Biosensors \& bioelectronics, 2012, 33: 120-127.

[5] H. Wang, L. Wang, C. Qu, Y. Su, S. Yu, W. Zheng, Y. Liu, Photovoltaic properties of graphene oxide sheets beaded with $\mathrm{ZnO}$ nanoparticles [J]. Journal of Solid State Chemistry, 2011, 184: 881-887.

[6] M. Chen, Z. B. Wang, K. Zhou, Y. Y. Chu, Synthesis of Pd/C Catalyst by Modified Polyol Process for Formic Acid Electrooxidation [J]. Fuel Cells, 2010, 10: 1171-1175.

[7] H. Li, S. Gan, D. Han, W. Ma, B. Cai, W. Zhang, Q. Zhang, L. Niu, High performance Pd nanocrystals supported on SnO2decorated graphene for aromatic nitro compound reduction [J]. Journal of Materials Chemistry A, 2014, 2: 3461-3467.

[8] H. J. Shin, K. K.Kim, A. Benayad, K. K. Kim, A. Benayad, S. M.Yoon, H. K. Park, I. S. Jung, M. H. Jin, H. K.Jeong, J. M. Kim, J. Y. Choi, Y. H. Lee, Efficient Reduction of Graphite Oxide by Sodium Borohydride and Its Effect on Electrical Conductance [J]. Adv. Funct. Mater, 2009, 19: 1987-1992.

[9] M.Yuan, A. Liu, M. Zhao, W. Dong, T. Zhao, J. Wang, W.Tang, Bimetallic $\mathrm{PdCu}$ nanoparticle decorated three-dimensional graphene hydrogel for non-enzymatic amperometric glucose sensor [J]. Sensors and Actuators B: Chemical, 2014, 190: 707-714.

[10] J. Chang, L. Feng, C. Liu, W. Xing, X. Hu, An Effective PdNi2P/C Anode Catalyst for Direct Formic Acid Fuel Cells [J] Angew. Chem. Int. Ed. 2014, 53: 122-126.

[11] M.Wienecke, M.C. Bunescu, M. Pietrzak, K. Deistung, P. Fedtke, PTFE membrane electrodes with increased sensitivity for gas sensor applications [J]. Synthetic Metals, 2003, 138: 165-171. 